\title{
Bortezomib Retreatment in Relapsed Multiple Myeloma - Results from a Retrospective Multicentre Survey in Germany and Switzerland
}

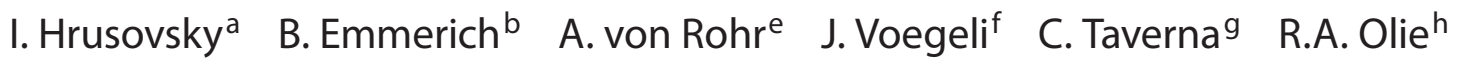 \\ H. Pliskat ${ }^{c}$ C. Frohn ${ }^{c}$ G. Hess ${ }^{d}$ \\ a Diakonie-Krankenhaus, Schwäbisch Hall, b Oncology Practice, Munich, ' Ortho Biotech, Division of Janssen-Cilag \\ $\mathrm{GmbH}$, Neuss, and dJohannes Gutenberg University, Mainz, Germany; ${ }^{\mathrm{C} O n k o z e n t r u m ~ H i r s l a n d e n, ~ Z u r i c h, ~}$ \\ ${ }^{f}$ Oncology Practice, La Chaux-de-Fonds, ${ }^{9}$ Kantonsspital, Münsterlingen, and h Janssen-Cilag AG, Baar, Switzerland
}

\section{Key Words}

Bortezomib $\cdot$ Multiple myeloma, relapsed $\cdot$ Retreatment

\begin{abstract}
Objectives: This multicenter, retrospective survey evaluated the efficacy and safety of bortezomib retreatment in patients with relapsed multiple myeloma who had responded to initial bortezomib treatment. Methods: Clinical records of 94 patients receiving bortezomib retreatment in Germany and Switzerland were reviewed. Results: Sixty patients were included according to prespecified criteria. Patients had received a mean $3.7 \pm 2.3$ therapies prior to initial bortezomib. Overall response rate to bortezomib retreatment was $63.3 \%$; 8 (13.3\%), 3 (5.0\%) and 27 (45.0\%) patients achieved complete response (CR), near-CR and partial response, respectively. $\mathrm{Re}$ sponse to retreatment was associated with response to initial treatment $(75.0 \%$ of patients with CR to initial treatment responded to retreatment) and treatment-free interval (TFI) after initial treatment (76.9 vs. $38.1 \%$ overall response rate for patients with TFI $>6$ vs. $\leq 6$ months). After retreatment, median time to progression was 9.3 months. Median TFI was 5.7 months; 31.7, 25.0 and $15.0 \%$ of patients experienced a TFI longer than 6, 9 and 12 months, respectively. Reported adverse drug reactions were consistent with the known safety profile of bortezomib and most resolved completely. Con-
\end{abstract}

clusions: These results demonstrate that relapsed multiple myeloma patients who respond to initial bortezomib treatment have a sustained susceptibility to bortezomib and do not experience uncommon toxicity to retreatment.

Copyright $\odot 2011$ S. Karger AG, Basel

\section{Introduction}

Despite recent treatment advances, multiple myeloma (MM) remains an incurable malignancy, and patients develop a progressively relapsing disease [1]. Formerly, MM therapies were often used until disease stabilization before being reinitiated upon disease progression. However, with the advent of several new therapeutic options, treatment regimens are often changed at every line of treatment. Patients may therefore remain sensitive and benefit from re-exposure, making retreatment an attractive therapeutic option.

The novel agent bortezomib (VELCADE ${ }^{\circledR}$; Millennium Pharmaceuticals, Inc., Cambridge, Mass., USA; Janssen-Cilag International NV, Beerse, Belgium) is approved by the US Food and Drug Administration and the European Medicines Agency for the treatment of MM in the frontline and relapsed/refractory settings [2]. Importantly, single-agent bortezomib has a demonstrated survival

\section{KARGER}

Fax +4161306 1234 E-Mail karger@karger.ch www.karger.com

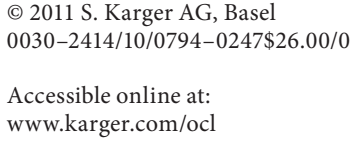

Dr Irena Hrusovsky

Diakonie-Krankenhaus

Diakoniestrasse 10

DE-74523 Schwäbisch Hall (Germany)

Tel. +49 791753 4486, Fax +49 791753 4485, E-Mail Irena.Hrusovsky@ diaksha.de 
benefit in relapsed/refractory MM [3]; in the updated analysis of the phase III APEX trial, single-agent bortezomib was associated with prolonged median overall survival (OS) versus high-dose dexamethasone. Standard treatment with single-agent bortezomib in the relapsed setting comprises eight 3 -week cycles, with dosing on days 1, 4, 8 and 11 [2]. Given this finite treatment course, patients may remain sensitive to bortezomib after relapse following initial treatment. Results from two US retrospective studies $[4,5]$ and preliminary findings of the phase II prospective international RETRIEVE study [6] have suggested that retreatment with bortezomib after previous bortezomib single-agent or combination regimens is feasible and can be effective, resulting in substantial clinical response rates and no new or cumulative toxicity, although further confirmation is required.

This survey is the first binational, multicenter, retrospective survey in the European clinical practice setting to assess the efficacy and safety profiles of bortezomib as retreatment in MM patients who had responded to prior bortezomib treatment.

\section{Patients and Methods}

\section{Patients and Study Design}

This was a retrospective, multicenter, single-arm survey conducted at 36 centers in Germany and Switzerland (26866138MMY4014). Patient clinical records were reviewed and patients who met the following criteria were included: aged $\geq 18$ years with relapsed MM; previously treated with bortezomib and achieved at least a partial response (PR); completed retreatment with bortezomib after relapse or disease progression; provided information about any MM-specific therapy between both bortezomib therapies; received no antineoplastic or immunomodulatory agents as concomitant therapy during bortezomib retreatment.

\section{Data Collection and Assessment}

All patients known to have received bortezomib retreatment at participating centers in Germany and Switzerland were considered for inclusion (safety population). Protocol-specified data were extracted from patient clinical records; all data had been collected between 10th September 2004 and 4th July 2008. The following parameters were documented: demographic and diseaserelated data, including age, gender, date of diagnosis, type of myeloma and number of prior therapies; bortezomib data for each exposure, including dose, duration of treatment, best response and response criteria used for assessment; administration of concomitant medication; disease progression following initial bortezomib treatment; adverse drug reactions (ADRs) attributed to bortezomib up to 30 days following the last dose of bortezomib. Bortezomib dose and schedule of administration, as well as methods and criteria for assessment of response, were at the discretion of the treating physician due to the retrospective nature of the survey. Following data review, any patients with major survey plan deviations were excluded from the per-protocol population.

\section{Statistical Analyses}

Before statistical analysis, and according to the prespecified data validation plan, the data were checked for plausibility, both visually and using SAS v8.2 software. Implausible data were corrected by manual checks, technical corrections and queries. Queries not resolved by data cutoff were considered as missing values. The safety population included all patients who received bortezomib retreatment, and was used for safety analyses. The per-protocol population included all patients who met all survey criteria, and was used for efficacy analyses.

Data were summarized descriptively using SAS v8.2 software. Categorical data were analyzed by frequency tables; adjusted frequencies (excluding missing values) and nonadjusted frequencies were calculated. Incidence rates were calculated with $95 \%$ confidence intervals $(95 \% \mathrm{CI})$. Continuous data were used to calculate the mean, standard deviation, median, minimum, maximum and quartiles.

Uncensored data were analyzed by standard descriptive statistics to determine time to response after initial bortezomib treatment and retreatment, and duration of response (DOR), time to progression (TTP) and treatment-free interval (TFI; time from end of initial bortezomib treatment to start of bortezomib retreatment or MM-specific interim therapy) after initial bortezomib treatment. Censored data were analyzed using the Kaplan-Meier method to estimate TTP, DOR, TFI and OS after retreatment.

\section{Results}

\section{Patient Characteristics and Disposition}

A total of 94 patients were identified from review of clinical records as having received bortezomib retreatment and were included in the safety population. Survey plan deviations were reported for 34 patients; these patients were excluded from the efficacy analysis, leaving 60 patients in the per-protocol population. The most common reason for exclusion was concomitant use of antineoplastic or immunomodulatory therapies (22 patients). Other reasons included ongoing retreatment (9 patients), no response to initial bortezomib treatment (6 patients), missing information about MM-specific interim therapy (6 patients), continuous bortezomib treatment (3 patients) and no confirmation of progression after initial bortezomib treatment ( 2 patients; more than one reason was applicable to some patients).

Patient demographic and disease characteristics were similar for the safety and per-protocol populations (table 1$)$. In the safety population, the mean $( \pm S D)$ age at start of bortezomib retreatment was $65.5 \pm 10.4$ years. Patients had received a mean $( \pm S D) 3.7 \pm 2.3$ therapies (range 1-13) prior to initial bortezomib treatment. The 
Table 1. Patient demographic and disease characteristics

\begin{tabular}{lcc}
\hline & $\begin{array}{c}\text { Safety } \\
\text { population } \\
(\mathrm{n}=94)\end{array}$ & $\begin{array}{c}\text { Per-protocol } \\
\text { population } \\
(\mathrm{n}=60)\end{array}$ \\
\hline Male & $53(56.4)$ & $33(55.0)$ \\
Mean age at diagnosis, years & $60.9 \pm 11.1$ & $60.4 \pm 11.4$ \\
& $(38-87)$ & $(38-87)$ \\
Mean age at start of initial & $65.5 \pm 10.4$ & $65.7 \pm 10.8$ \\
bortezomib treatment, years & $(40-89)$ & $(43-89)$ \\
Myeloma type & $52(55.3)$ & $34(56.7)$ \\
IgG & $22(23.4)$ & $15(25.0)$ \\
IgA & $17(18.1)$ & $8(13.3)$ \\
L-chain & $2(2.1)$ & $2(3.3)$ \\
Nonsecretory & $1(1.1)$ & $1(1.7)$ \\
Plasmocytic & $47.7 \pm 34.7$ & $51.9 \pm 39.2$ \\
Mean time from diagnosis to initial & $(3.9-176.1)$ & $(3.9-176.1)$ \\
bortezomib treatment, months & $3.7 \pm 2.3$ & $3.7 \pm 2.4$ \\
Mean number of therapies prior to & $(1-13)$ & $(1-13)$ \\
initial bortezomib treatment & & \\
Most common prior therapies & $42(44.7)$ & $26(43.3)$ \\
Melphalan-prednisone & $36(38.3)$ & $25(41.7)$ \\
Dexamethasone & $30(31.9)$ & $21(35.0)$ \\
VAD & $25(26.6)$ & $16(26.7)$ \\
Stem cell transplant & $21(22.3)$ & $13(21.7)$ \\
Thalidomide & $17(18.1)$ & $13(21.7)$ \\
Thalidomide-dexamethasone & $11(11.7)$ & $10(16.7)$ \\
$\alpha$-Interferon & $2(2.1)$ & $1(1.7)$ \\
DVD & $72(76.6)$ & $40(66.7)$ \\
Other & & \\
\hline
\end{tabular}

Figures in parentheses are percentages or ranges.

$\mathrm{VAD}=$ Vincristine-adriamycin-dexamethasone; DVD = doxorubicin-vincristine-dexamethasone.

most common prior therapies were melphalan-prednisone $(44.7 \%)$, dexamethasone $(38.3 \%)$ and vincristineadriamycin-dexamethasone (31.9\%); $26.6 \%$ of patients had previously undergone stem cell transplantation.

\section{Initial Bortezomib Treatment and Interim Anti-MM \\ Therapy}

Patients in the per-protocol population received a mean ( $\pm \mathrm{SD}$ ) $4.7 \pm 2.3$ (range 1-12) cycles of initial bortezomib treatment (table 2); the majority of patients $(85.0 \%)$ received bortezomib $1.3 \mathrm{mg} / \mathrm{m}^{2}$, and $81 \%$ of patients received bortezomib according to the standard dosing schedule of days $1,4,8$ and 11 of a 21-day cycle. During initial bortezomib treatment, $33.3 \%$ of patients received concomitant dexamethasone (table 2).

Per inclusion criteria, all patients in the per-protocol population had achieved at least a partial response to ini-
Table 2. Exposure to bortezomib and other anti-MM therapy

\begin{tabular}{|c|c|c|}
\hline & $\begin{array}{l}\text { Safety } \\
\text { population } \\
(\mathrm{n}=94)\end{array}$ & $\begin{array}{l}\text { Per-protocol } \\
\text { population } \\
(\mathrm{n}=60)\end{array}$ \\
\hline \multicolumn{3}{|l|}{ Initial bortezomib treatment } \\
\hline \multicolumn{3}{|l|}{ Mean bortezomib exposure } \\
\hline Cycles & $5.8 \pm 8.3$ & $4.7 \pm 2.3$ \\
\hline Range & $1-80$ & $1-12$ \\
\hline \multicolumn{3}{|l|}{ Number of cycles } \\
\hline $1-3$ & $30(31.9)$ & $21(35.0)$ \\
\hline $4-6$ & $45(47.9)$ & $30(50.0)$ \\
\hline $7-9$ & $13(13.8)$ & $7(11.7)$ \\
\hline$\geq 10$ & $6(6.4)$ & $2(3.3)$ \\
\hline \multicolumn{3}{|l|}{ Bortezomib dose } \\
\hline $1.3 \mathrm{mg} / \mathrm{m}^{2}$ & $80(85.1)$ & $51(85.0)$ \\
\hline $1.0 \mathrm{mg} / \mathrm{m}^{2}$ & $8(8.5)$ & $7(11.7)$ \\
\hline Other & $10(10.6)$ & $4(6.7)$ \\
\hline Concomitant dexamethasone & $41(43.6)$ & $20(33.3)$ \\
\hline \multicolumn{3}{|l|}{ Bortezomib retreatment } \\
\hline \multicolumn{3}{|l|}{ Mean bortezomib exposure } \\
\hline Cycles & $4.5 \pm 3.4$ & $4.1 \pm 2.5$ \\
\hline Range & $1-19$ & $1-14$ \\
\hline \multicolumn{3}{|l|}{ Number of cycles } \\
\hline $1-3$ & $39(42.9)$ & $29(48.3)$ \\
\hline $4-6$ & $37(40.7)$ & $22(36.7)$ \\
\hline $7-9$ & $10(11.0)$ & $7(11.7)$ \\
\hline$\geq 10$ & $5(5.5)$ & $2(3.3)$ \\
\hline \multicolumn{3}{|l|}{ Bortezomib dose } \\
\hline $1.3 \mathrm{mg} / \mathrm{m}^{2}$ & $74(78.7)$ & $48(80.0)$ \\
\hline $1.0 \mathrm{mg} / \mathrm{m}^{2}$ & $13(13.8)$ & $11(18.3)$ \\
\hline Other ${ }^{\mathrm{a}}$ & $6(6.4)$ & $2(3.3)$ \\
\hline Concomitant dexamethasone & $59(62.8)$ & $33(55.0)$ \\
\hline Other concomitant medications & $46(48.9)$ & $21(35.0)$ \\
\hline \multicolumn{3}{|l|}{ Antineoplastic and } \\
\hline immunomodulating agents & $22(23.4)$ & 0 \\
\hline Musculoskeletal system & $20(21.3)$ & $15(25.0)$ \\
\hline Anti-infectives for systemic use & $8(8.5)$ & $5(8.3)$ \\
\hline Alimentary tract and metabolism & $6(6.4)$ & $5(8.3)$ \\
\hline
\end{tabular}

Figures in parentheses are percentages.

${ }^{a}$ More than one dose recorded for some patients.

tial bortezomib therapy; 12 patients (20.0\%) had achieved complete response (CR), 7 (11.7\%) near-CR (nCR) and 41 (68.3\%) PR (table 3). In most patients (44 patients, 73.3\%), response assessment was according to changes in $\mathrm{M}$ protein only; however, some were assessed by European Group for Blood and Marrow Transplantation (EBMT) and Eastern Cooperative Oncology Group (ECOG) criteria [9 (15\%) and $6(10 \%)$ patients, respectively]. Median time to best response with initial bortezomib treatment was 3.1 months (range 0.4-9.0). Median DOR was 6.9 

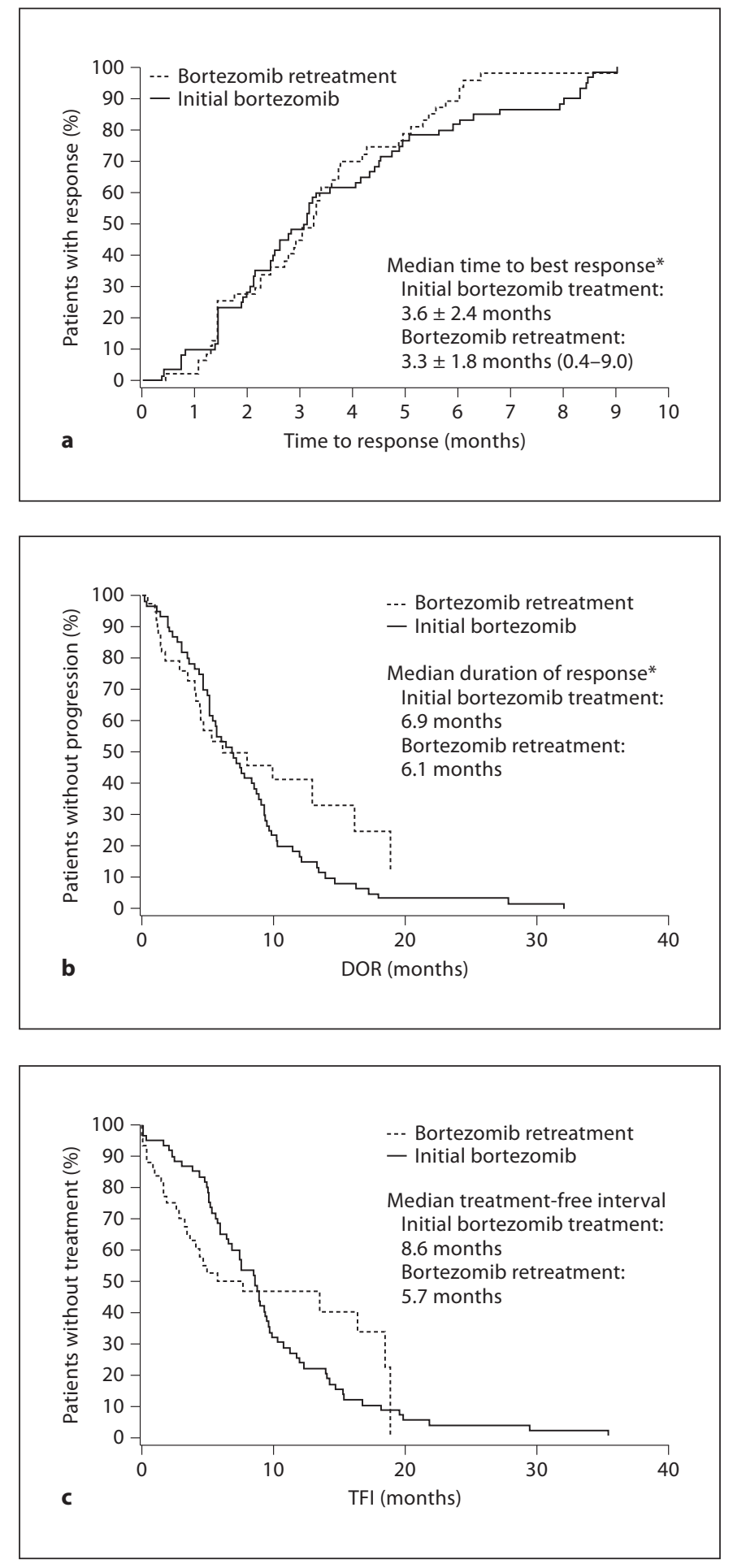

Fig. 1. Time to best response (a), DOR (b) and TFI (c) with initial bortezomib therapy and bortezomib retreatment. ${ }^{*}$ Analysis based on 47 patients; 12 patients who developed progressive disease and 1 patient missing date of response data were excluded. months (range 0.2-32.0), median TFI was 8.6 months (range 0.03-35.4) and median TTP was 10.9 months (fig. 1).

Between initial bortezomib treatment and retreatment, $8(13.3 \%)$ patients received MM-specific interim therapy; 2 patients underwent allogeneic peripheral blood stem cell transplantation, 1 underwent autologous stem cell transplantation, 2 received melphalan and 1 each received alemtuzumab-fludarabine-melphalan, bendamustine, cyclophosphamide, cyclophosphamide-vincristine-prednisone, lenalidomide, melphalan-prednisone, thalidomide-dexamethasone-cyclophosphamide and thalidomide-melphalan-prednisolone (some patients received more than one MM-specific therapy).

\section{Bortezomib Retreatment}

Patients in the per-protocol population received a mean $4.1 \pm 2.5$ cycles of bortezomib as retreatment (range 1-14); the majority (85.0\%) received 1-6 cycles (table 2). Thirty-three $(55.0 \%)$ patients received concomitant dexamethasone and $35.0 \%$ of patients received other concomitant medications during bortezomib retreatment (table 2). Response assessment was according to changes in M-protein only in most patients (40 patients, 66.7\%); EBMT criteria and ECOG criteria were used in 8 $(13.3 \%)$ and $3(5.0 \%)$ patients, respectively (table 3$)$.

The overall response rate $(\mathrm{CR}+\mathrm{nCR}+\mathrm{PR})$ to bortezomib retreatment was 63.3\% (95\% CI 49.9-75.4) (table 3). Eight (13.3\%), 3 (5.0\%) and 27 (45.0\%) patients achieved CR, nCR and PR, respectively, and a further 10 (16.7\%) patients had stable disease, for a clinical benefit rate of $80 \%$ (95\% CI 67.7-89.2).

Retreatment response rate was evaluated according to response to initial bortezomib treatment, TFI following initial bortezomib treatment ( $>6$ vs. $\leq 6$ months) and use of concomitant dexamethasone with bortezomib retreatment (yes vs. no). Of the patients who achieved CR (12 patients), nCR (7 patients) or PR (41 patients) to initial bortezomib therapy, 9 (75.0\%), 4 (57.1\%) and 25 (61.0\%), respectively, responded to bortezomib retreatment $(\geq \mathrm{PR})$ (table 4). Notably, 4 patients achieved a CR/nCR with bortezomib retreatment following a previous $\mathrm{PR}$ with initial bortezomib treatment. Analysis of response according to TFI after initial bortezomib treatment showed that the response rate was markedly higher in the subgroup with TFI $>6$ months than in the subgroup with TFI $\leq 6$ months ( 76.9 vs. $38.1 \%$, respectively); the $\mathrm{CR} / \mathrm{nCR}$ rate was 23.1 and $9.5 \%$ for patients with TFI $>6$ months and TFI $\leq 6$ months, respectively (table 5). Concomitant dexamethasone therapy did not affect the response rate 
Table 3. Efficacy of initial bortezomib treatment and bortezomib retreatment

\begin{tabular}{ccc}
\hline & $\begin{array}{c}\text { Initial bortezomib } \\
\text { therapy } \\
(\mathrm{n}=60)\end{array}$ & $\begin{array}{c}\text { Bortezomib } \\
\text { retreatment } \\
(\mathrm{n}=60)\end{array}$ \\
\hline $\begin{array}{cc}\text { Overall response rate } \\
\text { 95\% CI }\end{array}$ & $60(100)$ & $38(63.3)$ \\
CR & $12(20.0)$ & $49.9-75.4$ \\
95\% CI & $10.8-32.3$ & $8(13.3)$ \\
nCR & $7(11.7)$ & $5.9-24.6$ \\
95\% CI & $4.8-22.6$ & $3(5.0)$ \\
PR & $41(68.3)$ & $1.0-13.9$ \\
95\% CI & $55.0-79.7$ & $27(45.0)$ \\
Stable disease & N/A & $10(16.7)$ \\
95\% CI & & $8.3-28.5$ \\
Progressive disease & N/A & $12(20.0)$ \\
95\% CI & & $10.8-32.3$ \\
Response criteria used & & $40(66.7)$ \\
M-protein & $44(73.3)$ & $8(13.3)$ \\
EBMT & $9(15)$ & $3(5.0)$ \\
ECOG & $6(10)$ & $8(13.3)$ \\
Other & $6(10)$ &
\end{tabular}

Figures in parentheses are percentages.

${ }^{a}$ More than one set of response criteria used for some patients; bortezomib retreatment response criteria not reported for 4 patients.

(64.7 vs. $61.5 \%$ for those who did vs. those who did not receive concomitant dexamethasone) (table 5).

Median time to best response to bortezomib retreatment was 3.3 months (range 0.4-9.0 months) (fig. 1). Median DOR to bortezomib retreatment was 6.1 months (fig. 1); however, $35.2 \%$ of patients had not progressed at data cutoff. Median TTP was 9.3 months. Median TFI after bortezomib retreatment was 5.7 months; $31.7,25.0$ and $15.0 \%$ of patients experienced a TFI longer than 6,9 and 12 months, respectively.

\section{Overall Survival}

In the safety population $(\mathrm{n}=94)$, median OS after first diagnosis, initial bortezomib treatment and bortezomib retreatment was 9.6, 3.3 and 1.6 years, respectively. In the per-protocol population $(n=60)$, the corresponding data were 11.1, 3.3 and 1.7 years, respectively. Overall, 30 patients had died at the time of data cutoff.

\section{Safety}

Forty-two patients in the safety population (44.7\%) experienced a total of 120 ADRs. The most common were
Table 4. Response rates to bortezomib retreatment stratified by response to initial bortezomib treatment

\begin{tabular}{ccccccc}
\hline \multicolumn{7}{c}{ Best response to bortezomib retreatment } \\
\cline { 2 - 7 } & ORR & CR & nCR & PR & $\begin{array}{l}\text { stable } \\
\text { disease }\end{array}$ & $\begin{array}{l}\text { progressive } \\
\text { disease }\end{array}$ \\
\hline Response to initial bortezomib & & & & \\
CR & $12(20.0)$ & 6 & 1 & 2 & 1 & 2 \\
nCR & $7(11.7)$ & 0 & 0 & 4 & 0 & 3 \\
PR & $41(68.3)$ & 2 & 2 & 21 & 9 & 7 \\
\hline
\end{tabular}

Figures in parentheses are percentages.

$\mathrm{ORR}=$ Overall response rate.

peripheral neuropathy (including peripheral neuropathy, peripheral sensory neuropathy, neuropathy, polyneuropathy, paresthesia and hypoesthesia) and thrombocytopenia, which were reported by 15 and 8 patients, respectively (table 6). Other ADRs reported by more than 2 patients were fatigue, pyrexia, herpes zoster and anemia. The majority of the ADRs (55.0\%) were grade $1 / 2$; 5 patients $(5 \%)$ experienced grade 3 peripheral neuropathy and 3 patients (3\%) experienced grade $3 / 4$ thrombocytopenia. Most (66.7\%) ADRs had resolved completely by data cutoff; $50 \%$ of the neuropathy events with reported outcomes had resolved. Of the 120 ADRs, 39 were assessed by the treating physician as 'definitely', 46 as 'probably' and 29 as 'possibly' related to bortezomib treatment; others were not reported.

Bortezomib dose modification and interruption of therapy were required in 4 and 7 patients, respectively, and 10 patients required bortezomib discontinuation. Discontinuation was due to neuropathy in 6 patients; other reasons included or thostatic hypotension, vertigo, dizziness, diarrhea, herpes zoster infection, staphylococcal sepsis and pulmonary infection (more than 1 ADR was cited for some patients; no specific reason was provided for 1 patient).

Serious ADRs were reported for 10 (10.6\%) patients; 3 cases of thrombocytopenia, 2 cases of neuropathy, and 1 case each of pneumonia, pulmonary infection, syncope, arrhythmia, dyspnea, pulmonary edema, sepsis, multiorgan failure, asthenia, neutropenia and exanthema. Two patients died due to serious ADRs; these were assessed as definitely related to bortezomib in 1 patient (arrhythmia, dyspnea and pulmonary edema) and possibly related to bortezomib in the other (pneumonia, sepsis and multiorgan failure). 
Table 5. Response rates to bortezomib retreatment stratified by TFI after previous bortezomib therapy and concomitant dexamethasone

\begin{tabular}{|c|c|c|c|c|c|c|}
\hline & \multicolumn{6}{|c|}{ Best response to bortezomib retreatment } \\
\hline & ORR & $\mathrm{CR}$ & $\mathrm{nCR}$ & PR & stable disease & progressive disease \\
\hline \multicolumn{7}{|c|}{ TFI after previous bortezomib therapy } \\
\hline$\leq 6$ months $(\mathrm{n}=21)$ & $8(38.1)$ & $2(9.5)[1.2-30.4]$ & 0 & $6(28.6)[11.3-52.2]$ & $5(23.8)[8.2-47.2]$ & $8(38.1)[18.1-61.6]$ \\
\hline$>6$ months $(\mathrm{n}=39)$ & $30(76.9)$ & $6(15.4)[5.9-30.5]$ & $3(7.7)[1.6-20.9]$ & $21(53.8)[37.2-69.9]$ & $5(12.8)[4.3-27.4]$ & $4(10.3)[2.9-24.2]$ \\
\hline \multicolumn{7}{|c|}{ Concomitant dexamethasone } \\
\hline Yes $(\mathrm{n}=34)$ & $22(64.7)$ & $4(11.8)[3.3-27.5]$ & $2(5.9)[0.7-19.7]$ & 16 (47.1) [29.8-64.9] & $4(11.8)[3.3-27.5]$ & $8(23.5)[10.7-41.2]$ \\
\hline No $(n=26)$ & $16(61.5)$ & $4(15.4)[4.4-34.9]$ & $1(3.8)[0.1-19.6]$ & $11(42.3)[23.4-63.1]$ & $6(23.1)[9.0-43.6]$ & $4(15.4)[4.4-34.9]$ \\
\hline
\end{tabular}

Figures in parentheses are percentages, in brackets $95 \%$ CI. ORR $=$ Overall response rate.

Table 6. ADRs reported for more than two patients

\begin{tabular}{|c|c|c|c|c|c|c|}
\hline & \multirow{2}{*}{$\begin{array}{l}\text { Total } \\
\text { number of } \\
\text { patients }\end{array}$} & \multicolumn{5}{|c|}{ Severity of ADR (number of patients) } \\
\hline & & $\begin{array}{l}\text { grade } \\
1\end{array}$ & $\begin{array}{l}\text { grade } \\
2\end{array}$ & $\begin{array}{l}\text { grade } \\
3\end{array}$ & $\begin{array}{l}\text { grade } \\
4\end{array}$ & $\begin{array}{l}\text { not re- } \\
\text { ported }\end{array}$ \\
\hline Peripheral neuropathy ${ }^{a}$ & 15 & 1 & 7 & 5 & 0 & 2 \\
\hline Thrombocytopenia & 8 & 2 & 2 & 1 & 2 & 1 \\
\hline Fatigue & 6 & 0 & 5 & 0 & 0 & 1 \\
\hline Pyrexia & 4 & 1 & 2 & 1 & 0 & \\
\hline Herpes zoster & 3 & 0 & 2 & 1 & 0 & \\
\hline Anemia & 3 & 1 & 1 & 1 & 0 & \\
\hline
\end{tabular}

a Includes peripheral neuropathy, peripheral sensory neuropathy, neuropathy peripheral, neuropathy, polyneuropathy, neuropathic pain, paresthesia and hypoesthesia.

\section{Discussion}

This binational, multicenter survey represents the first retrospective review of bortezomib retreatment in the European clinical practice setting in MM patients who had responded to initial bortezomib treatment and reflects the daily experience in clinical practice. Although limited by the usual parameters associated with a retrospective analysis, including the potential risk of selection bias, the results presented here demonstrate the efficacy of bortezomib retreatment, with or without concomitant dexamethasone, in a heavily pretreated patient population with a mean of more than 3 treatment lines prior to initial bortezomib therapy. Per protocol, all patients had achieved at least PR to initial bortezomib treatment, and the majority (63.3\%) again responded to retreatment, including $18.0 \%$ who achieved a CR/nCR.
Response to bortezomib retreatment was most notable in patients with good response to initial bortezomib treatment, as patients who achieved a CR with initial bortezomib treatment were more likely to respond to retreatment and, specifically, to again achieve a CR. Additionally, a TFI $>6$ months versus a TFI $\leq 6$ months after initial treatment was associated with a superior overall response rate (76.9 vs. $38.1 \%$ ), and may be predictive of retreatment efficacy. Similar results were seen in a small retrospective study of bortezomib retreatment (overall response rates of 67 vs. $33 \%$ for TFI $>6$ vs. $\leq 6$ months) [5]. TFI after initial treatment is increasingly accepted as an indicator of the effectiveness of retreatment, and this association is reflected in the NCCN guidelines for salvage therapy in MM [7], which suggest that the primary induction therapy may be repeated if relapse occurs after more than 6 months.

Analysis of time-to-event data showed that bortezomib retreatment was associated with shorter TTP and TFI than was initial treatment (median TTP: 9.3 vs. 10.9 months; median TFI: 5.7 vs. 8.6 months). This is commonly observed with subsequent lines of therapy [1] due to the evolving disease biology of MM, in which the number of aggressive tumor cells with increased proliferation and decreased apoptotic rates increases with disease course [8]. As patients in the present study were heavily pretreated (mean $3.7 \pm 2.3$ therapies prior to initial bortezomib treatment), these differences in TTP and TFI likely reflect this progressive disease course. This progressive disease course may also account for the difference in response between patients with a TFI $>6$ months versus $\leq 6$ months following initial bortezomib treatment; the latter group may have a more aggressive disease phenotype. 
Importantly, however, in the 47 patients who reported clinical benefit ( $\geq$ stable disease) with both initial bortezomib treatment and bortezomib retreatment, the clinical benefit in terms of DOR to bortezomib retreatment appeared similar to that to initial bortezomib treatment. Response to bortezomib retreatment was rapid and durable, with median times to best response and DOR similar to those seen with initial bortezomib treatment. The median TTP after retreatment (9.3 months) also compares favorably with that seen in the phase 2 SUMMIT (7 months) $[9,10]$ and phase 3 APEX (6.2 months) trials [3], although comparisons between retrospective surveys and prospective studies should be interpreted with caution. Furthermore, median OS after first diagnosis (11.1 years) compares favorably with previous reports that most MM patients die within 10 years of diagnosis [1].

Bortezomib as retreatment was generally well tolerated and the reported ADRs and serious ADRs were consistent with safety profiles seen in previous phase II and III studies of bortezomib in relapsed $[3,9,11]$ and frontline MM [12]. The most common toxicities were peripheral neuropathy and thrombocytopenia, both of which are known to be associated with bortezomib and have been shown to be manageable. Peripheral neuropathy with bortezomib is often reversible in both the relapsed $[10,13,14]$ and frontline [15] settings, and in the present study, $50 \%$ of neuropathy events had resolved by data cutoff. With the use of established dose-modification guidelines [10], bortezomib-induced peripheral neuropathy is manageable and reversible in the majority of relapsed/ refractory MM patients [14] and, although in the present study dosing was at the discretion of the physician, it could be postulated that use of these guidelines would have obviated the need for bortezomib discontinuation due to peripheral neuropathy in a number of patients. Previous studies have also reported thrombocytopenia with bortezomib to be transient and cyclical [11, 16, 17] and that it may not require treatment interruptions and can be managed with platelet transfusions as clinically indicated $[16,17]$.

The results presented here support the preliminary findings of the recent phase II prospective RETRIEVE study, in which $51 \%$ of response-evaluable patients responded to bortezomib retreatment (as assessed by best confirmed response) [6]. However, it should be noted that all patients in the RETRIEVE study had a TFI $>6$ months after initial bortezomib treatment, a characteristic associated with increased response rates in the present survey. Importantly, our results reflect experience in the European clinical practice setting and are consistent with data from other retrospective bortezomib retreatment studies $[4,5,18,19]$. In particular, the overall response rate reported here $(63.3 \%)$ is similar to preliminary results of smaller, single-center studies, in which 12 of 19 (63.1\%) response-evaluable patients [19] and 6 of $10(60 \%)$ patients [18] responded to bortezomib retreatment. In retrospective studies in the USA, Conner et al. [4] reported that $32 \%$ of patients achieved VGPR/PR with bortezomib retreatment, and Wolf et al. [5] reported a 50\% response rate to bortezomib retreatment. Although these response rates would be expected to be lower due to the inclusion of patients who achieved $<\mathrm{PR}$ to initial bortezomib, some responses to bortezomib retreatment were even seen in these initial nonresponders $[4,5]$.

The efficacy of bortezomib retreatment also suggests that patients relapsing following initial bortezomib treatment are not intrinsically more 'resistant', and bortezomib treatment does not appear to select for a 'bortezomib-resistant' clone. This is particularly important due to the recent approval of bortezomib in previously untreated MM patients [2]. Data from the phase III VISTA study in newly diagnosed patients indicate that bortezomib retreatment is effective in patients who received bortezomib plus melphalan-prednisone as frontline therapy, suggesting that bortezomib retreatment may offer clinical benefit after relapse from bortezomib-based frontline therapy [15].

In conclusion, these results support the notion that bortezomib retreatment is a well-tolerated and effective therapeutic option for patients who have responded to initial treatment and that bortezomib treatment does not lead to resistance. The benefits of bortezomib retreatment seem particularly pronounced in patients who experienced an initial TFI of 6 months or more. Furthermore, following bortezomib treatment, it is not always necessary to switch therapies at relapse or avoid subsequent use of the increasingly popular bortezomib-based combination regimens.

\section{Acknowledgements}

The authors would like to thank all physicians who participated in this survey and acknowledge writing assistance of Jane Saunders of FireKite during the development of this publication, which was supported by funding from Millennium Pharmaceuticals, Inc. This work was supported by Janssen-Cilag GmbH. 


\section{References}

$>1$ Kumar SK, Therneau TM, Gertz MA, Lacy MQ, Dispenzieri A, Rajkumar SV, Fonseca R, Witzig TE, Lust JA, Larson DR, Kyle RA, Greipp PR: Clinical course of patients with relapsed multiple myeloma. Mayo Clin Proc 2004;79:867-874.

2 Velcade $^{\circledR}$ (bortezomib) for Injection. Prescribing Information. Cambridge, Millennium Pharmaceuticals, Inc., 2009.

3 Richardson PG, Sonneveld P, Schuster M, Irwin D, Stadtmauer E, Facon T, Harousseau JL, Ben-Yehuda D, Lonial S, Goldschmidt H, Reece D, Miguel JS, Blade J, Boccadoro M, Cavenagh J, Alsina M, Rajkumar SV, Lacy M, Jakubowiak A, Dalton W, Boral A, Esseltine DL, Schenkein D, Anderson KC: Extended follow-up of a phase 3 trial in relapsed multiple myeloma: final time-to-event results of the APEX trial. Blood 2007; 110:3557-3560.

$\checkmark 4$ Conner TM, Doan QD, Walters IB, LeBlanc AL, Beveridge RA: An observational, retrospective analysis of retreatment with bortezomib for multiple myeloma. Clin Lymphoma Myeloma 2008;8:140-145.

$\checkmark 5$ Wolf J, Richardson PG, Schuster M, LeBlanc A, Walters IB, Battleman DS: Utility of bortezomib retreatment in relapsed or refractory multiple myeloma patients: a multicenter case series. Clin Adv Hematol Oncol 2008;6: 755-760.

6 Petrucci MT, Blau IW, Corradini P, Dimopoulos MA, Drach J, Giraldo P, Teixeira A, Blade J: Efficacy and safety of retreatment with bortezomib in patients with multiple myeloma: interim results from RETRIEVE, a prospective international phase 2 study. Haematologica 2010;95:377a.

7 National Comprehensive Cancer Network (NCCN): NCCN Clinical Practice Guidelines in Oncology ${ }^{\mathrm{TM}}$. Multiple Myeloma (V.1.2011). Fort Washington, NCCN, 2010.

8 Drewinko B, Alexanian R, Boyer H, Barlogie B, Rubinow SI: The growth fraction of human myeloma cells. Blood 1981;57:333-338.
-9 Richardson PG, Barlogie B, Berenson J, Singhal S, Jagannath S, Irwin D, Rajkumar SV, Srkalovic G, Alsina M, Alexanian R, Siegel D, Orlowski RZ, Kuter D, Limentani SA, Lee S Hideshima T, Esseltine DL, Kauffman M, Adams J, Schenkein DP, Anderson KC: A phase 2 study of bortezomib in relapsed, refractory myeloma. N Engl J Med 2003;348: 2609-2617.

10 Richardson PG, Briemberg H, Jagannath S, Wen PY, Barlogie B, Berenson J, Singhal S, Siegel DS, Irwin D, Schuster M, Srkalovic G, Alexanian R, Rajkumar SV, Limentani S, Alsina M, Orlowski RZ, Najarian K, Esseltine D, Anderson KC, Amato AA: Frequency, characteristics, and reversibility of peripheral neuropathy during treatment of advanced multiple myeloma with bortezomib. J Clin Oncol 2006;24:3113-3120.

-11 Richardson PG, Sonneveld P, Schuster MW, Irwin D, Stadtmauer EA, Facon T, Harousseau JL, Ben-Yehuda D, Lonial S, Goldschmidt H, Reece D, San-Miguel JF, Blade J, Boccadoro M, Cavenagh J, Dalton WS, Boral AL, Esseltine DL, Porter JB, Schenkein D, Anderson KC: Bortezomib or highdose dexamethasone for relapsed multiple myeloma. N Engl J Med 2005;352:24872498.

12 San Miguel JF, Schlag R, Khuageva NK, Dimopoulos MA, Shpilberg O, Kropff M, Spicka I, Petrucci MT, Palumbo A, Samoilova OS, Dmoszynska A, Abdulkadyrov KM, Schots R, Jiang B, Mateos M-V, Anderson KC, Esseltine DL, Liu K, Cakana A, van de Velde H, Richardson PG: Bortezomib plus melphalan and prednisone for initial treatment of multiple myeloma. N Engl J Med 2008;359:906-917.

13 Jagannath S, Barlogie B, Berenson JR, Siegel DS, Irwin D, Richardson PG, Niesvizky R, Alexanian R, Limentani SA, Alsina M, Esseltine DL, Anderson KC: Updated survival analyses after prolonged follow-up of the phase 2, multicenter CREST study of bortezomib in relapsed or refractory multiple myeloma. Br J Haematol 2008;143:537-540.
14 Richardson PG, Sonneveld P, Schuster MW, Stadtmauer EA, Facon T, Harousseau JL, Ben-Yehuda D, Lonial S, Goldschmidt H, Reece D, Blade J, Boccadoro M, Cavenagh JD, Boral AL, Esseltine DL, Wen PY, Amato AA, Anderson KC, San MJ: Reversibility of symptomatic peripheral neuropathy with bortezomib in the phase III APEX trial in relapsed multiple myeloma: impact of a dosemodification guideline. Br J Haematol 2009; 144:895-903.

15 Mateos MV, Richardson PG, Schlag R, Khuageva NK, Dimopoulos MA, Shpilberg O, Kropff M, Spicka I, Petrucci MT, Palumbo A, Samoilova OS, Dmoszynska A, Abdulkadyrov KM, Schots R, Jiang B, Esseltine DL, Liu K, Cakana A, van de Velde H, San Miguel JF: Bortezomib plus melphalan and prednisone compared with melphalan and prednisone in previously untreated multiple myeloma: updated follow-up and impact of subsequent therapy in the phase III VISTA trial. J Clin Oncol 2010;28:2259-2266.

16 Lonial S, Richardson PG, San MJ, Sonneveld P, Schuster MW, Blade J, Cavenagh J, Rajkumar SV, Jakubowiak AJ, Esseltine DL, Anderson KC, Harousseau JL: Characterisation of haematological profiles and low risk of thromboembolic events with bortezomib in patients with relapsed multiple myeloma. $\mathrm{Br}$ J Haematol 2008;143:222-229.

17 Lonial S, Richardson P, Sonneveld P, Schuster M, Irwin D, Stadtmauer E, Facon T, Harousseau J, Ben-Yehuda D, Goldschmidt $\mathrm{H}$, Reece D, San MJ, Blade J, Boccadoro M, Cavenagh J, Dalton W, Boral A, Schenkein D, Anderson KC: Hematologic profiles in the phase 3 APEX trial. Blood 2005;106:970a.

-18 Ciolli S, Leoni F, Casini C, Bosi A: Feasibility and efficacy of bortezomib re-treatment in multiple myeloma. Haematologica 2007;92: $260 a$.

19 Rubio-Martinez A, Recasens V, Soria B, Montanes MA, Rubio-Escuin R, Giraldo P: Response to retreatment on relapse multiple myeloma patients previously treated with bortezomib. Haematologica 2008;93:649a. 